UCRL-ID-120664

\title{
Calibration of Density Logs at the Nevada Test Site
}

Joseph R Hearst

April 1995

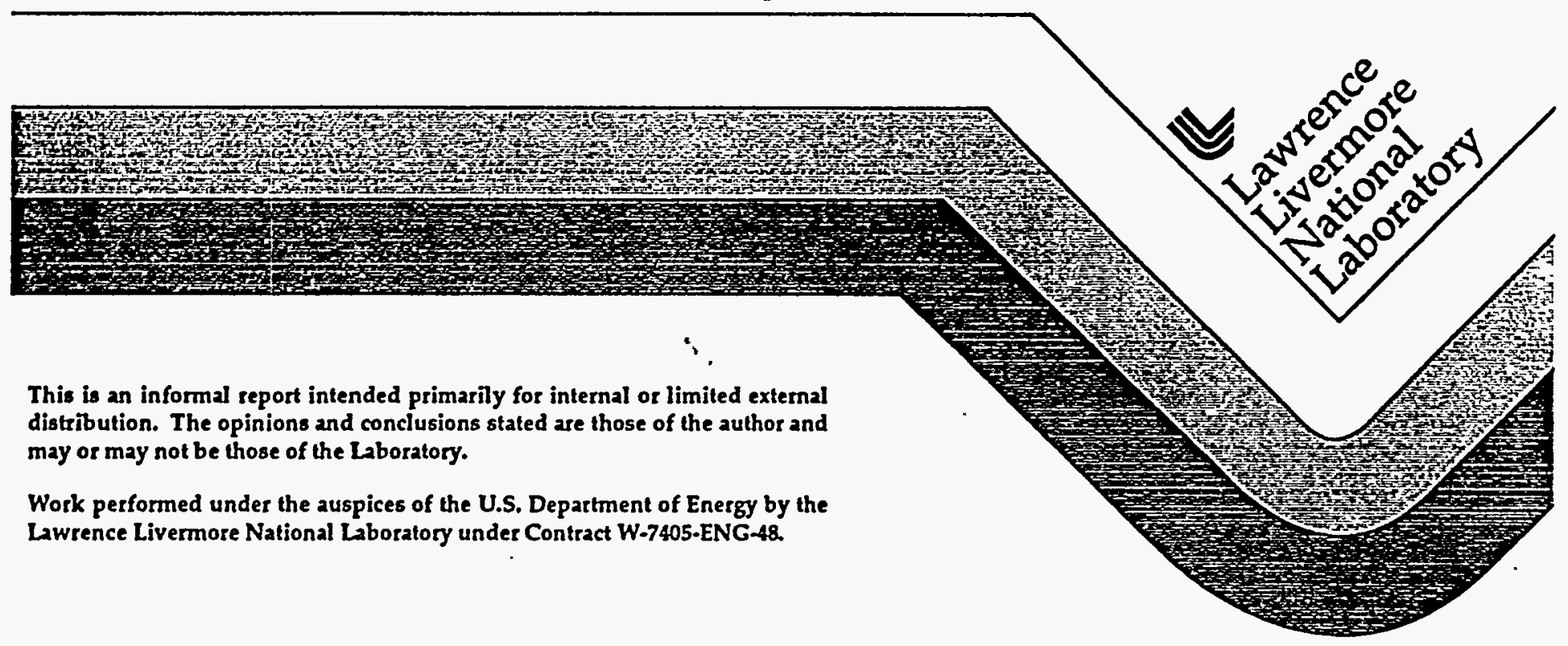




\section{DISCLAIMER}

This report was prepared as an account of work sponsored by an agency of the United States Government. Neither the United States Government nor any agency thereof, nor any of their employees, make any warranty, express or implied, or assumes any legal liability or responsibility for the accuracy, completeness, or usefulness of any information, apparatus, product, or process disclosed, or represents that its use would not infringe privately owned rights. Reference herein to any specific commercial product, process, or service by trade name, trademiark, manufacturer, or otherwise does not necessarily constitute or imply its endorsement, recommendation, or favoring by the United States Government or any agency thereof. The views and opinions of authors expressed herein do not necessarily state or reflect those of the United States Government or any agency thereof. 


\section{DISCLAIMER}

Portions of this document may be illegible in electronic image products. Images are produced from the best available original document. 


\title{
Calibration of Density Logs at the Nevada Test Site
}

\author{
Joseph R Hearst
}

\section{Introduction}

During the evaluation of a proposed site for an underground nuclear test at the Department of Energy's Nevada Test Site (NTS) it was important to measure the bulk density of the geological formation in which the test was to be executed. The most satisfactory method for this measurement is the density log (Hearst and Nelson, 1985). This is a measurement system in which a gamma-ray.source and detector are mounted in an instrument (a sonde) which is lowered into a borehole by a multi-conductor cable, and the number of gamma rays detected is used to infer the bulk density.

Many geophysical service companies offer density logs, but those logs are calibrated for the conditions that occur in the petroleum industry: liquid-filled boreholes with diameters between 7 and 40 $\mathrm{cm}$, drilled in saturated media, with the borehole often coated with mudcake. At NTS many of the boreholes of interest are air-filled, with diameters as large as $3.65 \mathrm{~m}$, drilled in partially-saturated media. Furthermore, many of the formations at NTS have bulk densities substantially lower than the densities commonly encountered in the petroleum industry. Consequently the commercial equipment and calibration procedures are not suitable for NTS conditions.

The count rate from a density sonde is strongly affected by any gap between the sonde and the borehole wall, especially if the gap is filled with air rather than water. Modern commercial density logs employ two detectors, and use one of the detectors to compensate for borehole conditions such as mudcake and gap (Hearst and Nelson, 1985.) The commercial compensation algorithms assume that the sonde is parallel to the borehole wall; a reasonable assumption for oilfield conditions but not for NTS conditions. Moreover, in an air-filled borehole, borehole diameter affects both the calibration and the compensation. Therefore we could not use commercial algorithms to deal with NTS conditions.

For many years, no appropriate two-detector algorithm was available for the NTS situation. Consequently we developed special algorithms for a single-detector sonde, which was equipped to measure the gap directly. Recently (Carlson, 1993) a twodetector algorithm was developed, which appears to be satisfactory if the sonde is calibrated in the appropriate-diameter borehole.

In this report we describe the calibration procedures and the algorithms for both methods.

\section{The logging sondes}

Figure 1 is a conceptual sketch of a conventional two-detector density sonde. The gamma-ray source and detectors are usually contained in a pad that is forced against the wall of the borehole. Gamma rays diffuse from source to detector through the formation and the borehole fluid; a small fraction reach the detector. Since it is much easier for gamma rays to travel through air than through water, a gap between the sonde and the formation causes a larger perturbation in an air-filled hole than in a waterfilled hole.

When we first began logging large holes we developed a sonde that had very tight collimation so that rather than diffusing through the formation all gamma rays reaching the detector were constrained to scatter only once. They passed through protuberances on the sonde which were designed so that there was no air gap (Hearst and Carlson, 1969.) This sonde gave good results, but could only be operated at selected depths rather than being pulled up the borehole continuously as is normal practice. Moreover it was difficult to operate and required a very large source. 
Therefore we developed special calibration procedures and our contractor built a large-diameter skid so that a commercial sonde could be used. It gave acceptable results but more accuracy was desired. Consequently two new versions of the commercial sonde were constructed.

For the very large holes at the NTS our logging contractor developed special mechanisms to force the sonde against the wall of the borehole. Figure 2 shows such a mechanism (the sonde shown is actually a neutron sonde.) There are four perpendicular sets of arms. The sonde is mounted on one. Large boreholes are frequently washed out in one direction, and if the sonde is run in the washed-out part of the hole the gaps will be larger than if it is run on a smoother part. Therefore the sonde is lowered to the bottom of the hole and the arms perpendicular to the sonde-bearing arm are opened first. As the sonde is pulled up the hole it rotates because of the standard design of the cable until the arms lock into the washout. Then the other set of arms is opened and the sonde is thereby forced against a smoother part of the hole.

One of the large-hole sondes is shown in Figure 3. This sonde, called the DRC, has one detector and three spring-loaded wheels that measure the gap. The single wheel is at the bottom of the sonde, and the source is above that wheel. The detector is between the two other wheels. The sonde used more often, the DBS, is similar to the DRC but there is a second detector in the position of the middle wheel of the DRC. The near detector is $39 \mathrm{~cm}$ from the source and the far detector is $58 \mathrm{~cm}$ from the source. The two sondes are actually mechanically somewhat different, and consequently their performance is also somewhat different; these differences will be discussed below.

\section{Calibration}

Before gap-correction algorithms can be used, the sonde must be calibrated for zero-gap conditions. Commercial sondes are commonly calibrated with aluminum $(2.62 \mathrm{~g} / \mathrm{cc}$ ) and magnesium $(1.74 \mathrm{~g} / \mathrm{cc})$ and sometimes with sulfur $(2.07 \mathrm{~g} / \mathrm{cc})$ to cover the range of densities in common oilfield formations. Because NTS densities tend to be in the range from 1.4 to $2.6 \mathrm{~g} / \mathrm{cc}$ we needed other calibrators. Our chemistry department constructed plastic blocks of bulk density $1.2,1.4$, and $2.13 \mathrm{~g} / \propto$. A density sonde actually measures electron density, which is the bulk density multiplied by $2 Z / A$, where $Z$ is the atomic number and $\mathrm{A}$ the atomic mass. The electron density of $\mathrm{Al}$ and $\mathrm{Mg}$ is almost the same as the bulk density; for the plastic blocks the electron densities are 1.27, 1.48, and $2.14 \mathrm{~g} / \mathrm{cc}$. After they were built, the plastic blocks were examined with X-rays, and hundreds of voids, some as large as $8 \mathrm{~mm}$ in diameter, were found. Therefore it must be recognịed that the blocks are not strictly uniform.

All of the calibration blocks are approximately $96 \mathrm{~cm}$ long and the cross section is a 30-cm square. A cylindrical groove with a radius of curvature of $61 \mathrm{~cm}$ is milled into one surface of each block to simulate a $122-\mathrm{cm}$-diameter borehole- the smallest hole that might be logged with this equipment The entire range of blocks was used to understand the behavior of the sonde. Ordinarily only the Al, $\mathrm{Mg}$, and $1.48 \mathrm{~g} / \mathrm{cc}$ blocks are used for calibration. Figure 4 shows the DBS sonde on its trailer in calibration position over the blocks.

Commercial two-detector sondes have also been used in smaller holes at NTS. They are calibrated using the vendors' blocks, ordinarily $\mathrm{Al}$ and $\mathrm{Mg}$ similar in size to our blocks, but with 15 - or $30-\mathrm{cm}$ diameter semi-cylindrical grooves or cylindrical holes to simulate boreholes of those diameters. (A modification to our blocks, with a 43-cm groove, was planned but never built.) Often plastic sleeves to simulate mudcake can be inserted in the grooves.

The standard calibration curve for a single-detector density sonde with no borehole effects is a straight line on a semilogarithmic plot:

$$
c p s=A e^{-B p}
$$


where cps is the count rate in the detector, $p$ is the electron density, and A and B are constants. This expression, with count rate decreasing with increasing density, is satisfactory for the density range under oilfield conditions, but since the count rate must go to zero at $p=0$, at some point the curve must reverse slope. Therefore, when low densities are measured, a correction must be made because the calibration curve is not a true exponential. In fact, we do not know where the slope reverses for the DBS; the lowest density we have measured is that of water with an electron density of $1.11 \mathrm{~g} / \mathrm{c}$, at which we can observe some departure from linearity. However, for the single-scattering sonde that we built, the slope reversal occurs at about $0.45 \mathrm{~g} / \mathrm{cc}$.

\section{Efrects of gap between sonde and borehole wall}

We studied the effects of gap in two ways. Our primary method was to place spacers between the sonde and the calibration blocks, so that the sonde was parallel to the block. We found that if true density were plotted against apparent density for a given value of gap, the result could be fitted reasonably well by a series of straight lines, intersecting in a point (Hearst et al., 1970). Figure 5 shows a typical plot for the far detector of the DBS in air. (Note that we express the gap in inches, because all gap measurements are made in inches.) The intersection point in this case is close to $1 \mathrm{~g} / \mathrm{cc}$, but the intersection varies considerably with source-detector spacing and "borehole" fluid. For example, the intersection for the near detector in air is $0.56 \mathrm{~g} / \mathrm{cc}$.

In one experiment R. C. Carlson of LLNL (Carlson, 1987) tried to determine where, in the space between the source and detector, the gap is most important. On a flat face of the aluminum calibrator he laid two 30-cm-wide aluminum sheets, 0.25 inches thick, covering the width of the block, with a 2 inch (5 $\mathrm{cm}$ ) space between them, near one end of the block. This simulated a block with a 2-inch-wide, 0.25 inch-deep slot milled across the short direction of the block. He then placed the DBS sonde lengthwise on the long axis of the block, wth the source at the edge of the slot nearest the detectors. He compared the count rate in this situation with the count rate with no gap between the sheets. He then moved the slot in increments, bringing the slot closer to the detectors. Therefore, initially the source crossed the slot, and then later first the near and then the far detector crossed the slot.

Figure 6 shows the result. The largest effect of the gap occurs when the slot is near the source, but between the source and the detectors. Another large effect occurs shortly before each detector reaches the slot. Clearly, the parallel-gap calibration is not appropriate when there is a short gap near the source or the detector. Nevertheless, we use the parallel-gap algorithm because we cannot measure the gap in the positions of greatest interest.

\section{Data Processing}

Single-detector Sondes:

In our standard procedure for processing data from a sonde with one detector and two gapmeasuring devices, we first shift the count rate and gap data so that the values obtained as each sensor passes a given depth point are tagged with the same depth. Then we remove all gap values greater than 0.95 inches and less than -0.125 inches (the gap mechanism can go negative if there are protuberances on the borehole wall.) Next the gaps are smoothed with a 1.5-foot-wide box Hanning filter. After smoothing, the mean of the gap values is taken at each depth. (There is some evidence that a weighted average would be more satisfactory, but we have used an unweighted average.) If data from the DRC, which has three gap-measuring devices, are being processed, two passes are made through the program, one using the average from the two outer devices, and one using the data from the center device. 
The count rate data are corrected for dead time using the standard procedure for a nonparalyzable system (Hearst and Nelson, 1985) and then smoothed in the same way as the gap data. Raw density is then calculated using a simple exponential (Hearst and Nelson, 1985)

$$
\rho=A+B \ln c p s
$$

where cps is the count rate. The constants $A$ and $B$ are obtained using the calibration blocks. An empirical correction, originally determined from the shape of a calibration curve developed using all five calibration blocks and a water tank, is applied for the effect of nonlinearity at low density:

$$
\rho_{\text {corr }}=\rho_{\text {raw }}-\frac{1}{K_{1} \rho_{\text {raw }}-K_{2}}
$$

where $K_{1}=144.7$ and $K_{2}=134.0$. This expression is plotted in Figure 7.

Finally a gap correction, using the mathematical expression for the lines in Figure 5 (Hearst et al., 1970), is applied.

$$
\rho_{t}=C_{2}+\frac{\rho_{a}-C_{2}}{1-C_{1} G}
$$

where $\rho_{l}$ is the true density, $\rho_{2}$ is the apparent density (before correction), $G$ is the gap in inches, $C_{l}$ and $C_{2}$ are obtained from calibration $\left(C_{2}\right.$ is the point of intersection of the lines in Figure 5.)

After gap correction, all densities for which the average gap exceds a limit, normally 0.8 inches, are removed. No correction is made for electron density during processing of the density log; it is made when the entire suite of logs is brought together and the measured water content is available from a neutron log.

\section{Two-detector sondes:}

In our normal processing of data from a two-detector sonde, we convert the density obtained from our service company's two-detector algorithm to electron density, because that algorithm assumes the formation to be saturated limestone. This is done by reversing the standard electron density conversion (Hearst and Nelson, 1985) assuming saturated limestone. We then remove all data where the service company's correction exceeds limits that we accept: -0.05 and $+0.15 \mathrm{~g} / \mathrm{cc}$.

This procedure is not satisfactory if the hole is significantly greater than about $30 \mathrm{~cm}$ in diameter; the service company's algorithm gives implausible values. Moreover, we have found that severe rugosity causes the standard algorithm to produce incorrect data. Therefore $R$. C. Carlson of LLNL developed a new procedure for obtaining data from a two-detector sonde (Carlson, 1993.) This method uses an equation of the form commonly used by service companies (Hearst and Nelson, 1985),

$$
\rho_{t}=\rho_{f}+\alpha\left(\rho_{f}-\rho_{n}\right)
$$

where $\rho_{t}$ is the true density, $\rho_{f}$ is the density measured by the far detector, and $\rho_{n}$ is the density measured by the near detector. In the standard method, $\alpha$ is a constant; in Carlson's method $\alpha$ is allowed to vary depending on the ratio of the standard deviations of the measured densities in the two detectors over a selected depth interval. (Carlson points out that this method fails when gap is constant with depth, because the standard deviations are zero - a situation rarely encountered at the NTS.) When the two detectors are calibrated in blocks corresponding to the true diameter of the borehole this procedure has resulted in improved agreement between the density measured in nearby boreholes of different diameter in 
the same formations. It has also removed the effects of rugosity seen in logs processed by the standard method. It is still necessary, however, to calibrate the individual detectors in blocks with hole diameters similar to those of the boreholes being logged.

Again, no correction is made for electron density during processing of the density log; it is made when the entire suite of logs is brought together and the measured water content is available from a neutron log.

\section{Comparison among Logging Methods}

In one very rugose $2.4-\mathrm{m}$-diameter borehole we had the opportunity to compare three sondes and two methods of processing. Figure 8 shows three diameters as measured at $120^{\circ}$ angles by a caliper log. The plot has been smoothed with a $1-\mathrm{m}$ square smoother to remove the high-frequency rugosity. Note the periodic nature of the smoothed caliper $\log$ in the region between 150 and $300 \mathrm{~m}$.

The mean of the two gaps measured by the DBS, our standard sonde, is shown in Figure 9. The density calculated by our standard processing method is shown in Figure 10. Data from many depths are missing, because the algorithm removes data where the gap is greater than 0.8 inches When the DRC, our three-gap-wheel sonde, was used, the average of the two outer gap measurements resulted in the curve shown in Figure 11, and the computed density is shown in Figure 12. The noise is much less than for the DBS data, and the densities tend to be higher. Because gaps always cause a decrease in the apparent density, we believe that densities measured in rugose holes are always low, and therefore an increase in measured density is usually considered to be an improvement. When the center gap from the DRC (Fig. 13) was used, the density data (Fig. 14) appear even less noisy, although the density at the bottom is somewhat lower.

As a result of this comparison, although the DBS is our standard instrument, we decided to use the DRC when rugosity was a serious problem.

When we used Carlson's (1993) processing method on the data from the two detectors of the DBS (with no correction for measured gap) we obtained the curve shown in Figure 15. This method clearly preserves more data than the standard method. If the criterion that higher density is better is used, the method is a substantial improvement over our standard method.

\section{Conclusions}

It is necessary to correct for the gap between the logging sonde and the borehole wall when using a gamma-gamma density log in an air-filled hole. Two methods, one using data from a gap-measuring device and one using data from two detectors in a procedure somewhat different from that used in the logging industry have been used in the large, air-filled boreholes at the Nevada Test Site. The latter method appears to be more satisfactory for the rapidly varying gaps usually observed at NTS. If, however, the gap is more or less constant with depth this method will not work. Constant gap, however, implies that the sonde is either parallel to the borehole wall or is traveling up a smooth wall at a constant angle. If the sonde is parallel the standard commercial two-detector algorithm is satisfactory. If it is at a constant angle, neither method will work. Therefore, to obtain the best results, a procedure should be devised that uses the commercial algorithm if the sonde is parallel, our new procedure when the gap varies significantly, and deletes the data if the sonde is at a constant angle to the wall. This may require use of the existing gap-measuring devices in a semi-quantitative manner. 


\section{Acknowledgements}

R. C. Carlson and M. Millett of LLNL made major contributions to this work. J. Maissa of Birdwell (later of Atlas Wireline Services) designed the large-hole sondes, the clamping mechanism was proposed by $\mathbf{S}$. Clark of EG\&G. J. Richter of EG\&G developed many of the original calibration algorithms. This work was performed under the auspices of the U. S. Department of Energy by Lawrence Livermore National Laboratory under contract No. W-7405-Eng-48. The work was supported by the LLNL Nuclear Test Containment Program.

\section{References}

Carlson, R. C. , 1987, Personal Communication.

Carlson, R C., 1993, Maximum Likelihood Borehole Corrections for Dual-Detector Density Logs, Proc. Fifh International Symposium on Geophysics for Minerals, Geotechnical, and Environmental Applications, sponsored by the Minerals and Geotechnical Logging Society, Tulsa OK 24-28 October.

Hearst, J. R, and R. C. Carlson; 1969; The RIDS, a Density Logger for Rough Holes, Geophysics, v. 34, p. 222-234.

Hearst, J. R, R. C. Carlson and J. T. Rambo; 1970, K-Division Experimental Work Part 1: Geophysics Research for Underground Explostion Technology, Lawrence Livermore National Laboratory Report UCRL-50855.

Hearst, J. R, and P. H. Nelson; 1985, Well Logging for Physical Properties, McGraw-Hill, New York. 


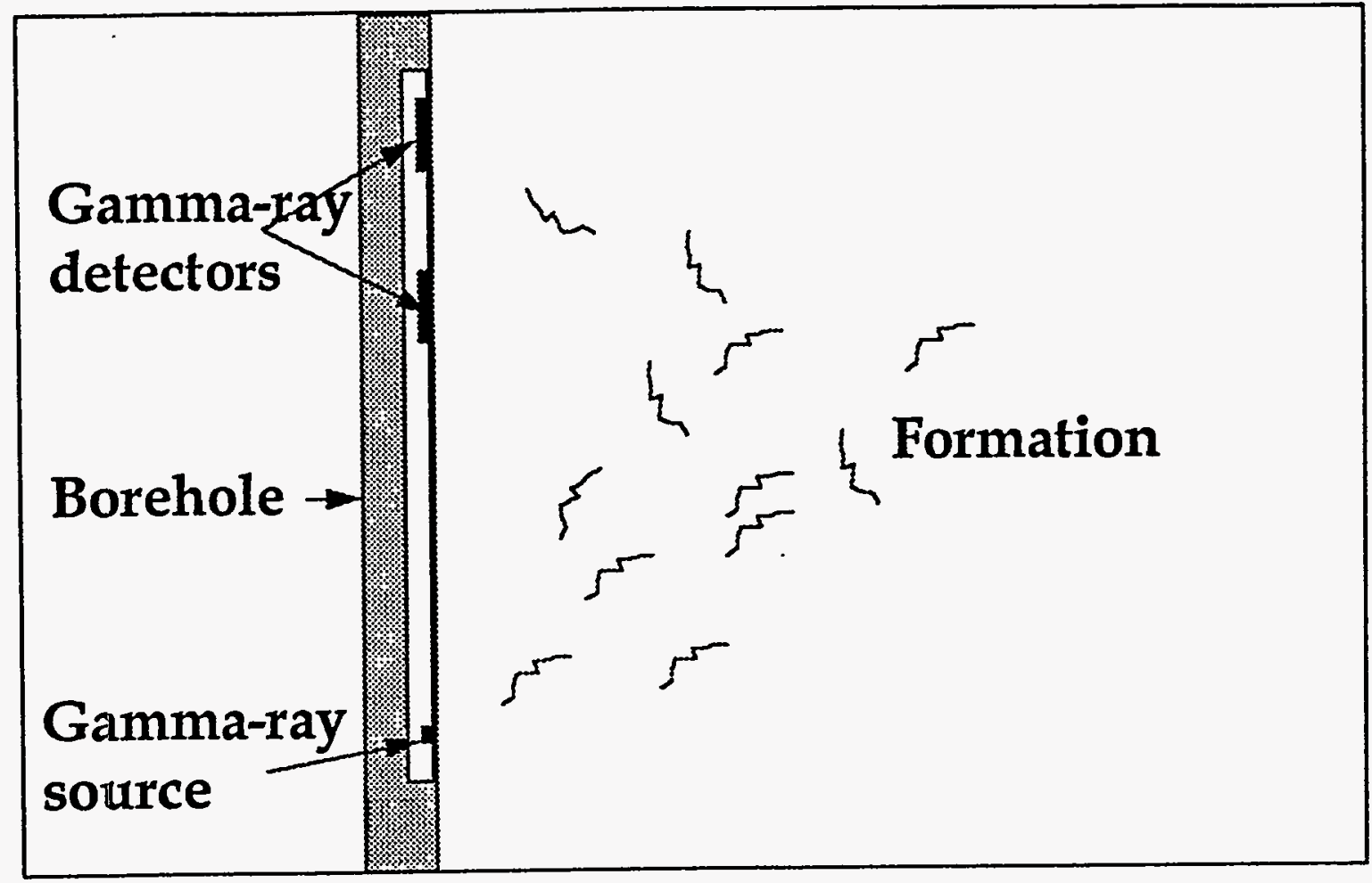

Figure 1. Conceptual sketch of a two-detector density sonde. 


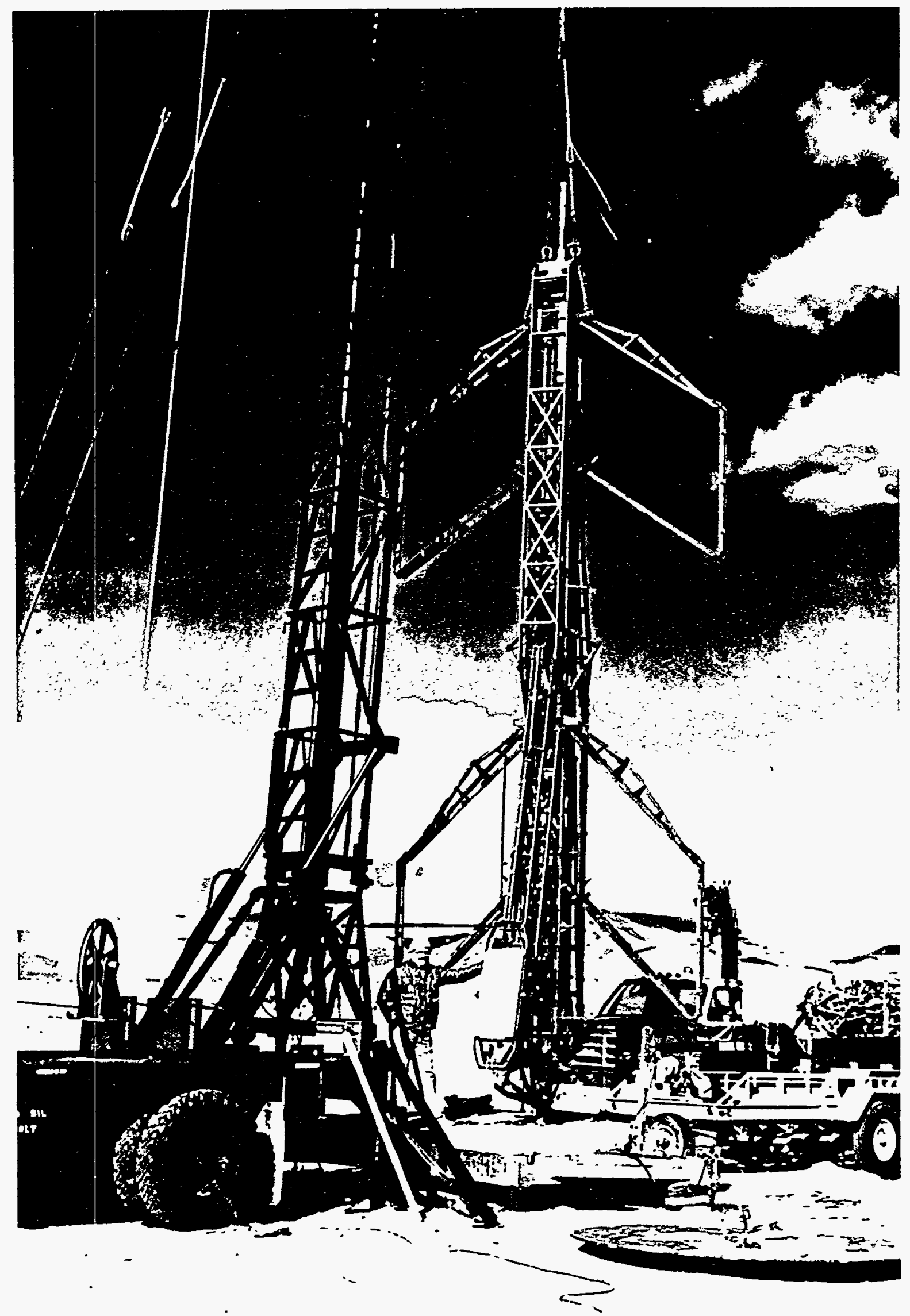

Figure 2. The borehole-locking mechanism of a large-hole sonde. (A neutron sonde is illustrated) 


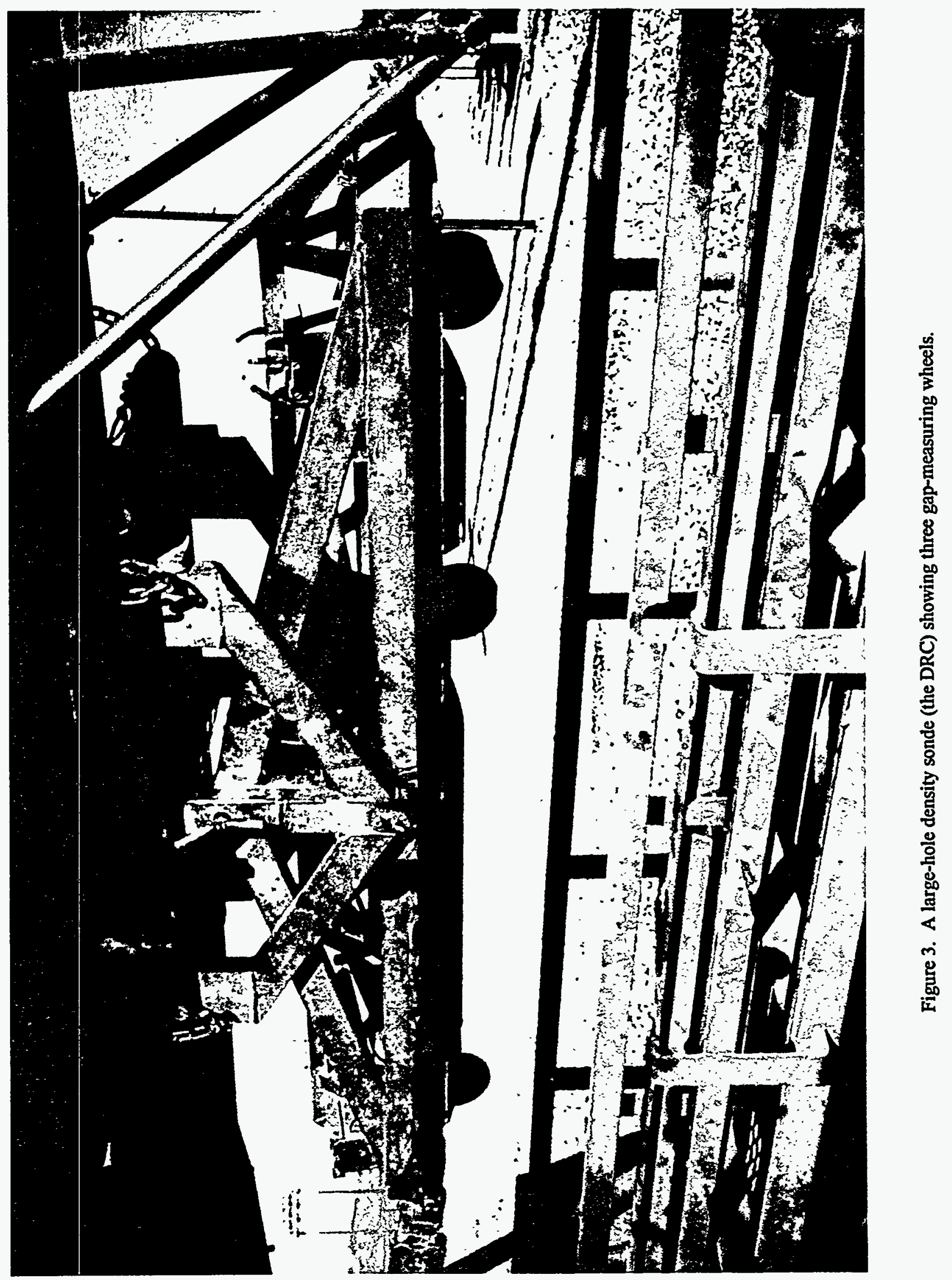




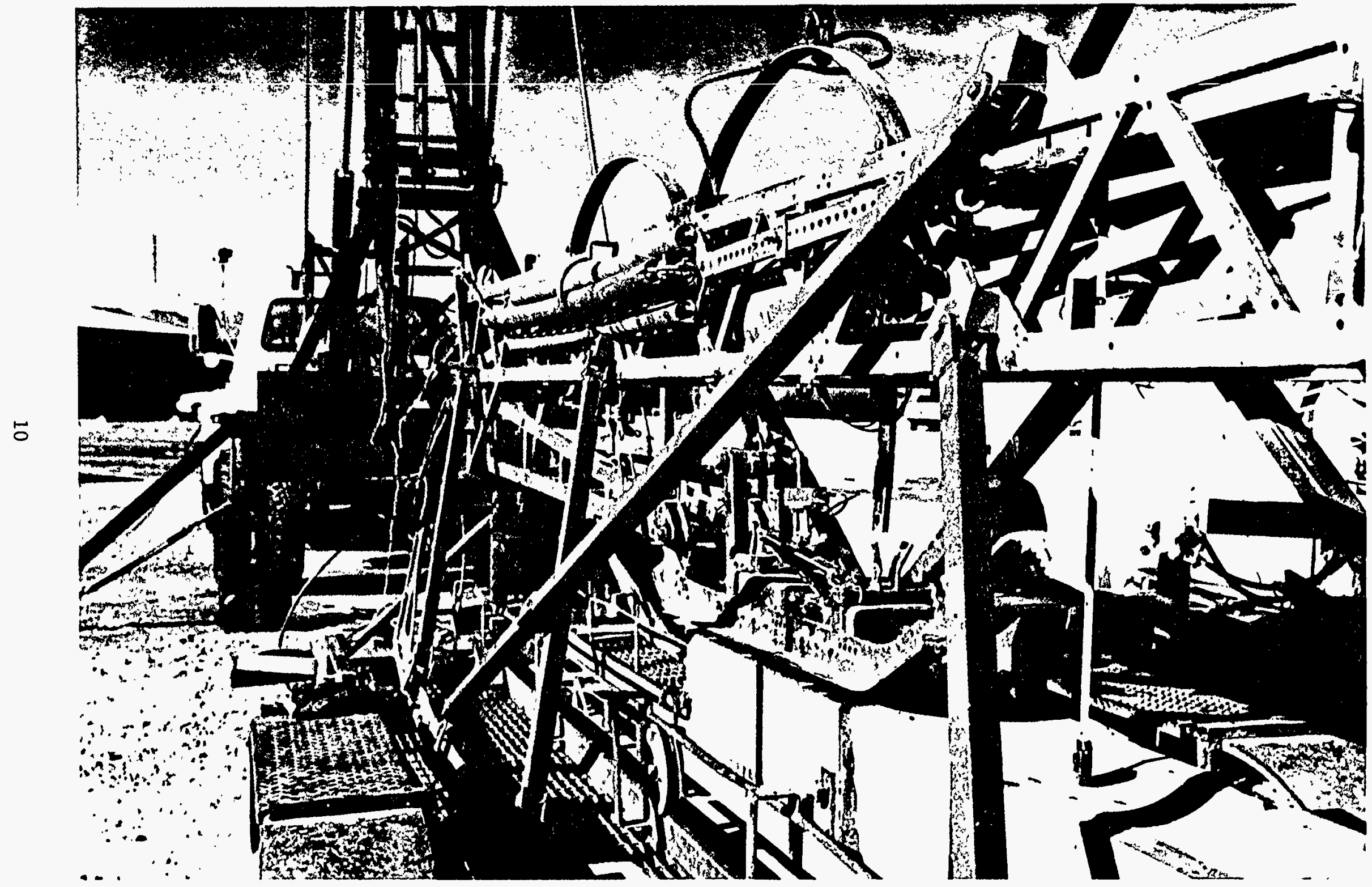

Figure 4. A large-hole density sonde (the DBS) on its trailer in calibration position above three calibration blocks. 


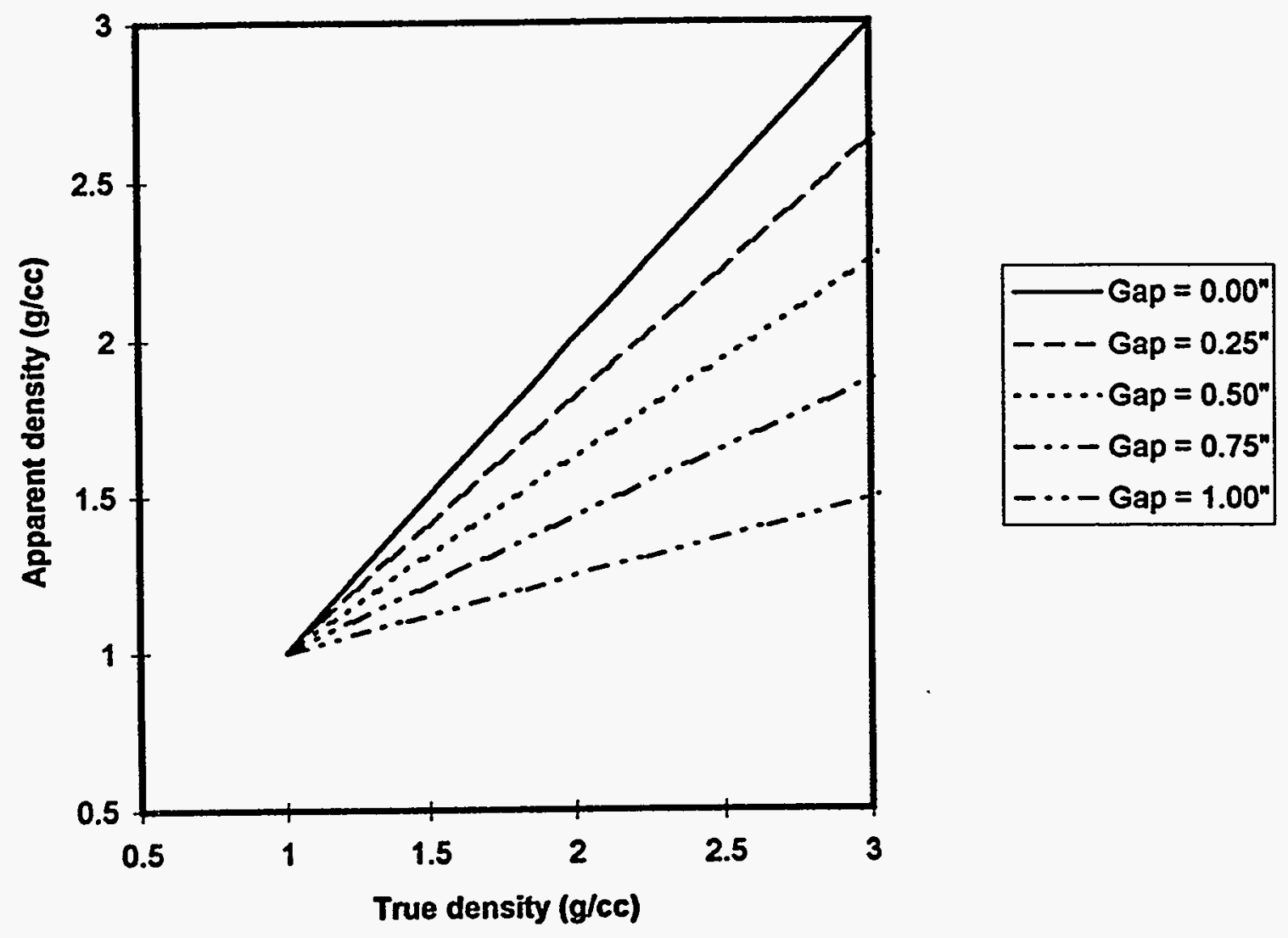

Figure 5. True density vs apparent density for different values of sonde-wall gap for a large-hole density sonde (the DBS.) Sonde is parallel to the calibrator. 


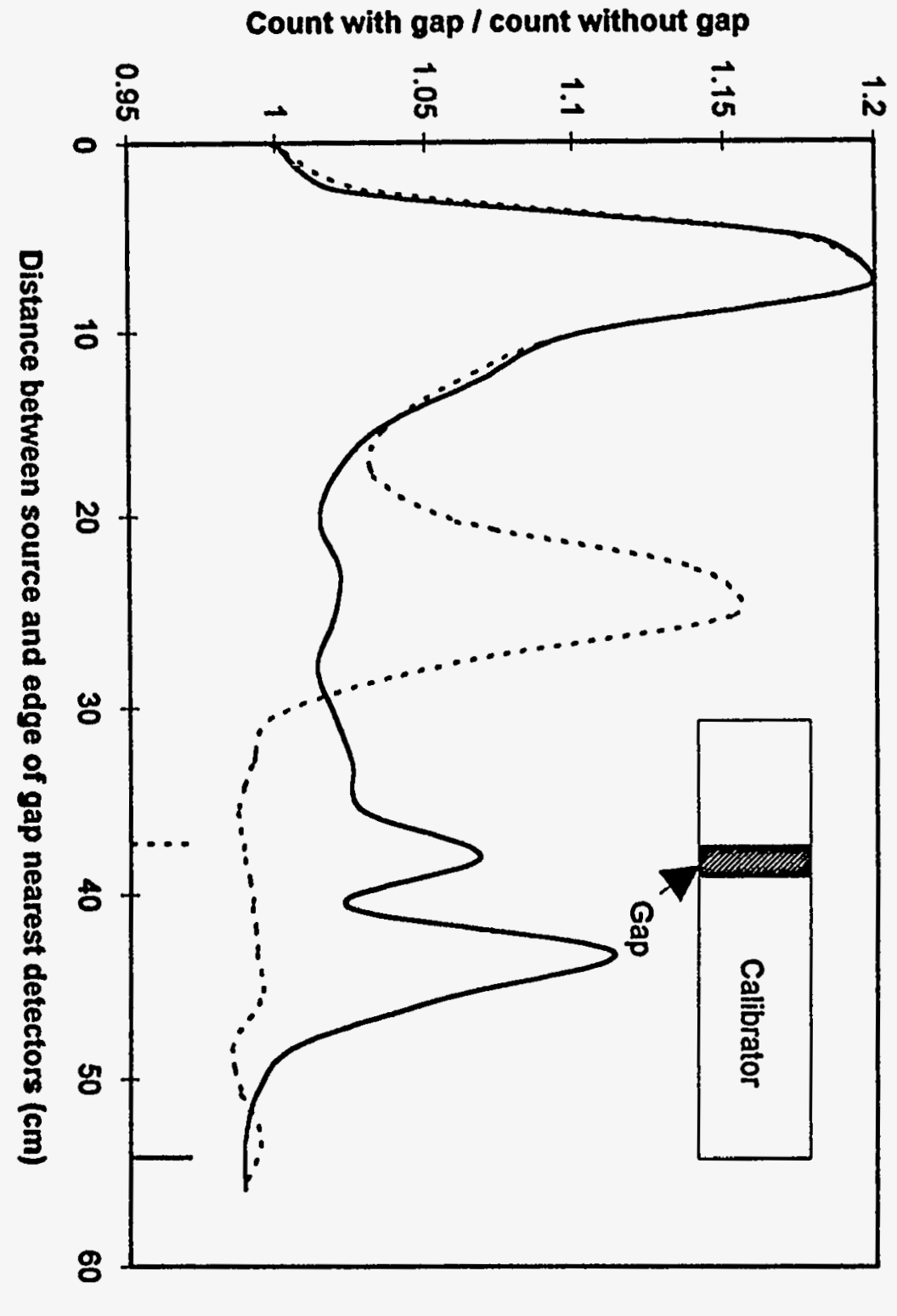




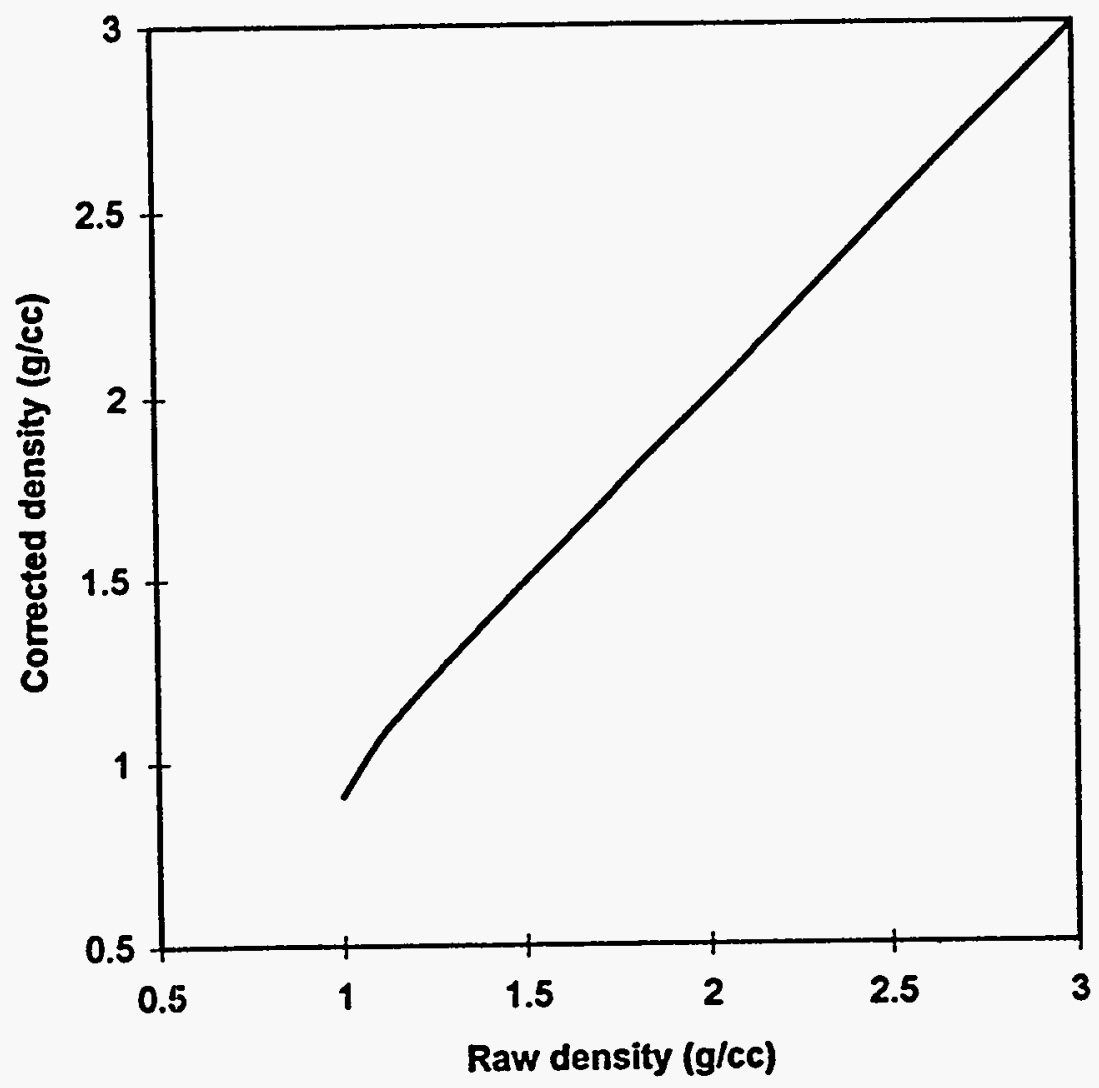

Figure 7. Correction for the effect of nonlinearity at low density. 

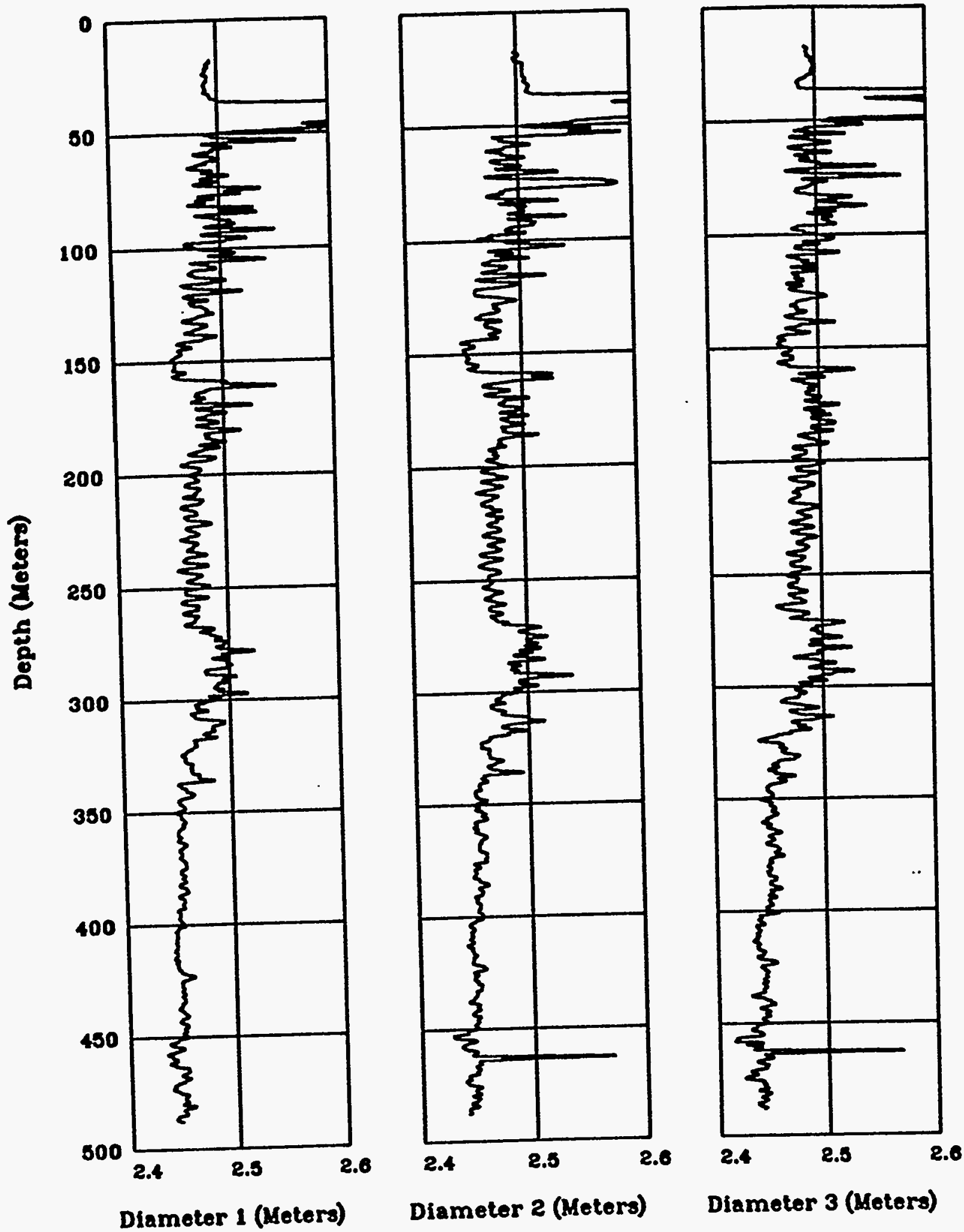

Figure 8. Caliper log showing diameter measured at $120^{\circ}$ intervals in borehole U2fg. Data smoothed with a $1-m$ square smoother. 


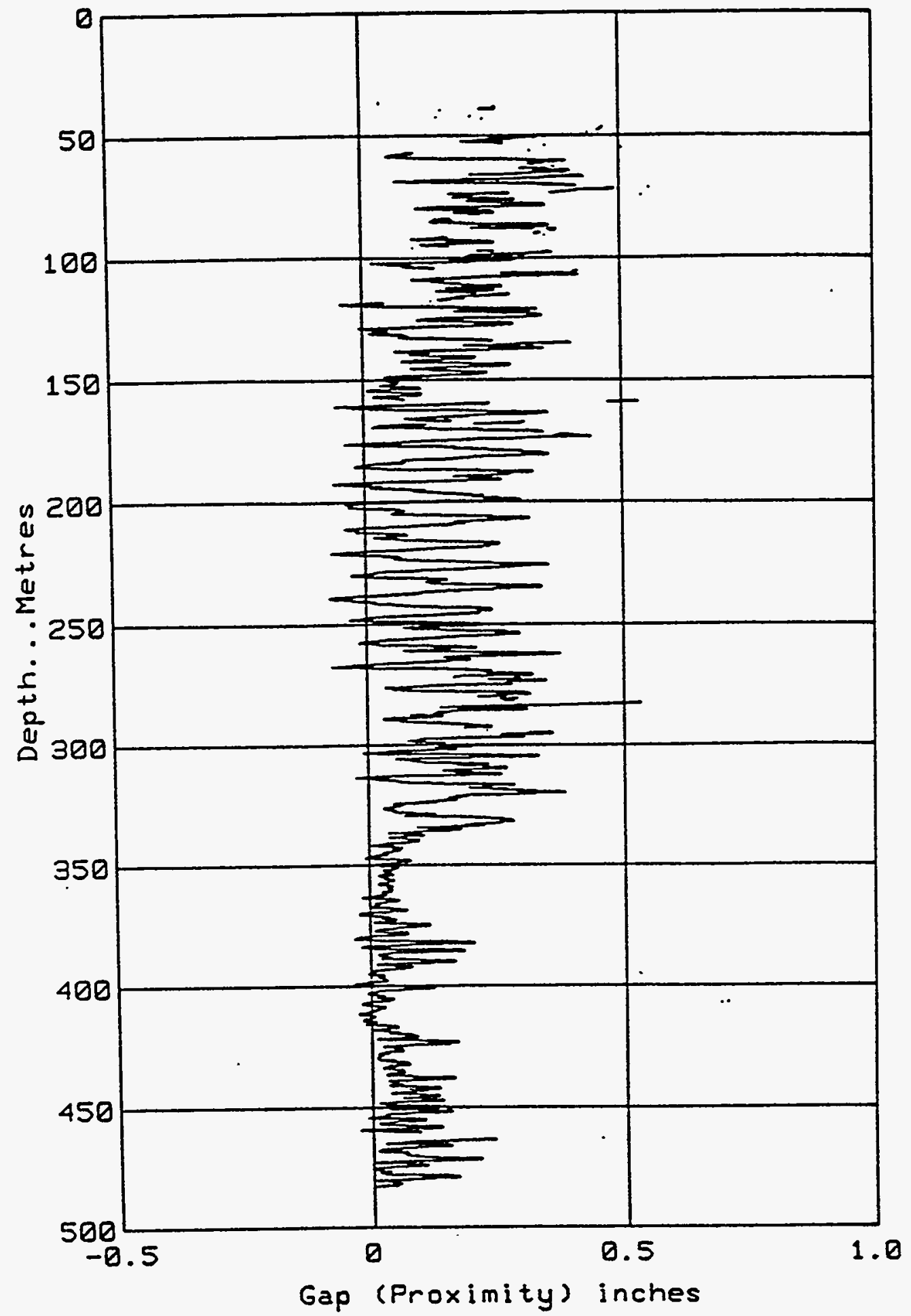

Figure 9. Average sonde-wall gap measured by the DBS sonde in borehole U2fg. Data smoothed with a 1m square smoother. 


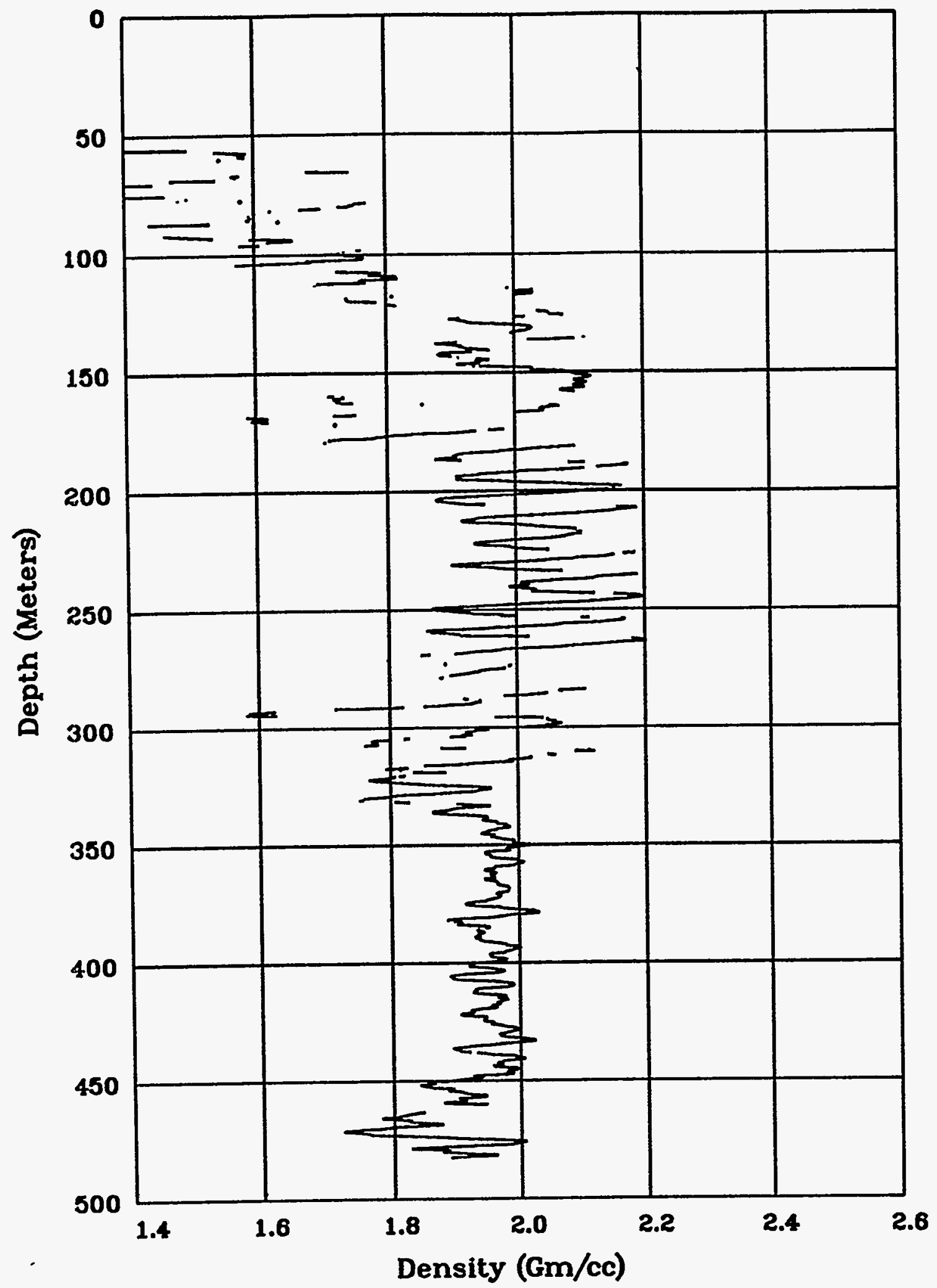

Figure 10. Density from standard processing of the DBS log in borehole U2fg. Data smoothed with a 3m square smoother. 


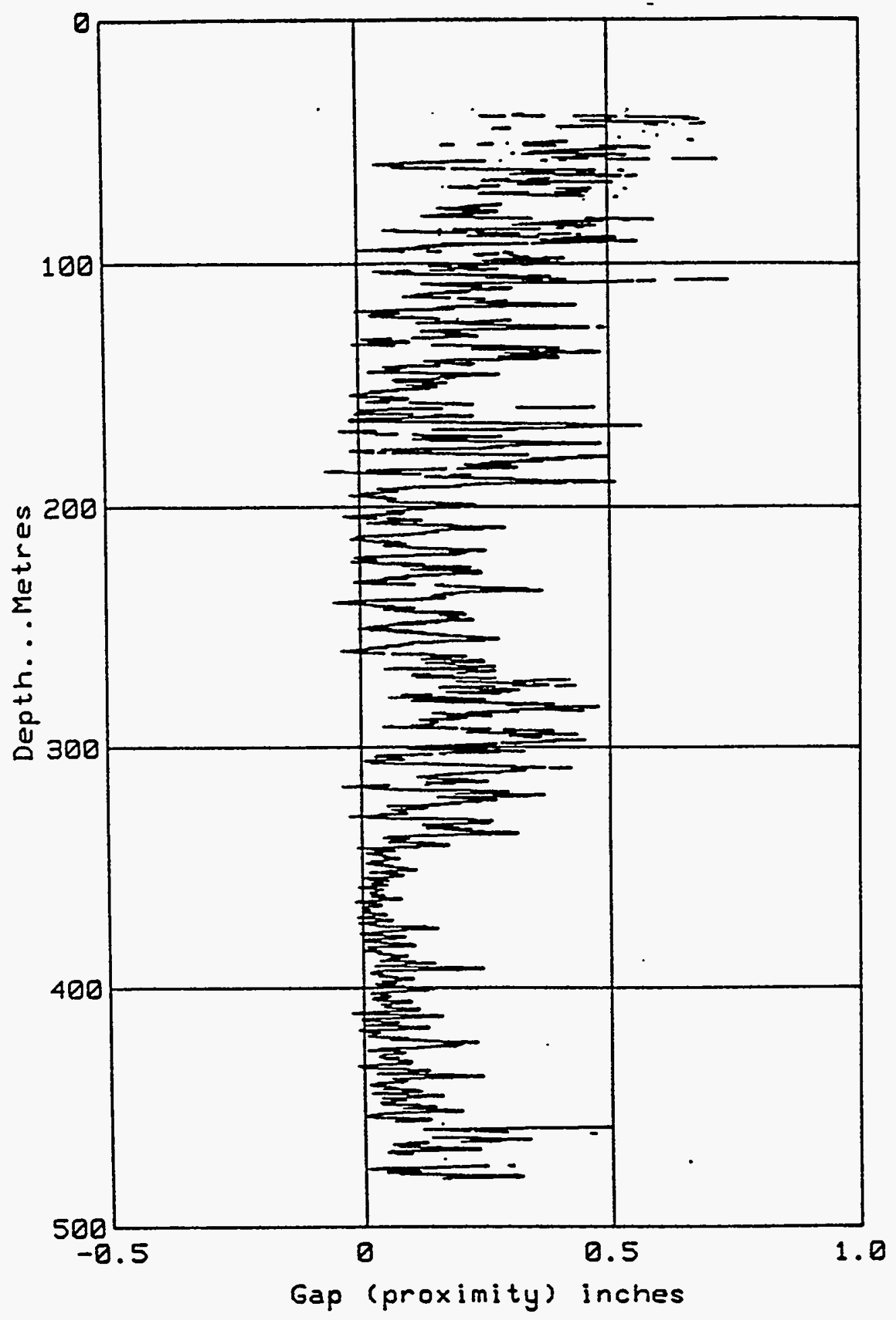

Figure 11. Average of the two outer sonde-wall gap measurements for the DRC sonde in borehole U2fg. Data smoothed with a 1-m square smoother. 


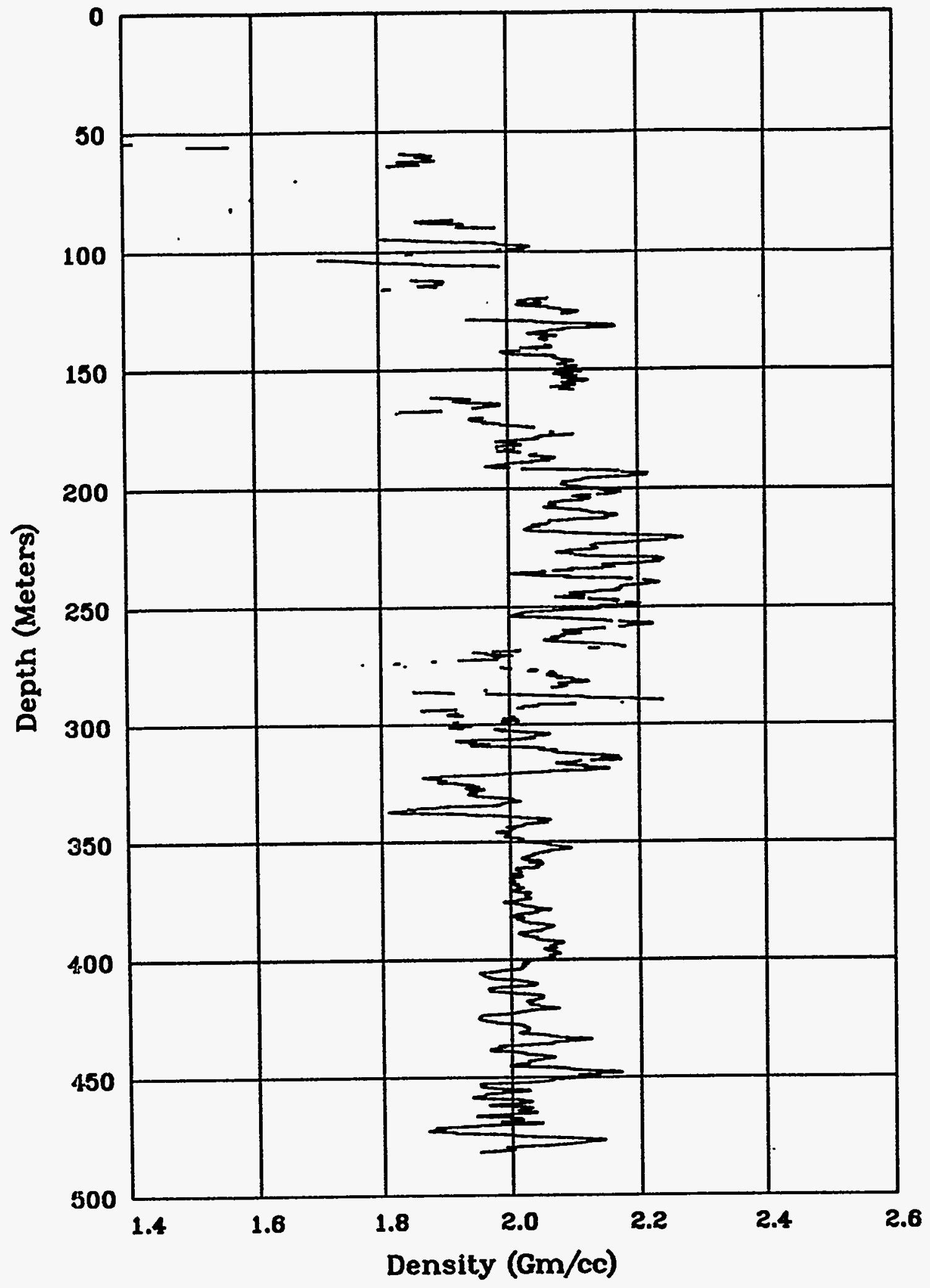

Figure 12. Density from standard processing of the DRC $\log$ in borehole U2fg, using the average of the two outer gap measurements. Data smoothed with a 3-m square smoother. 


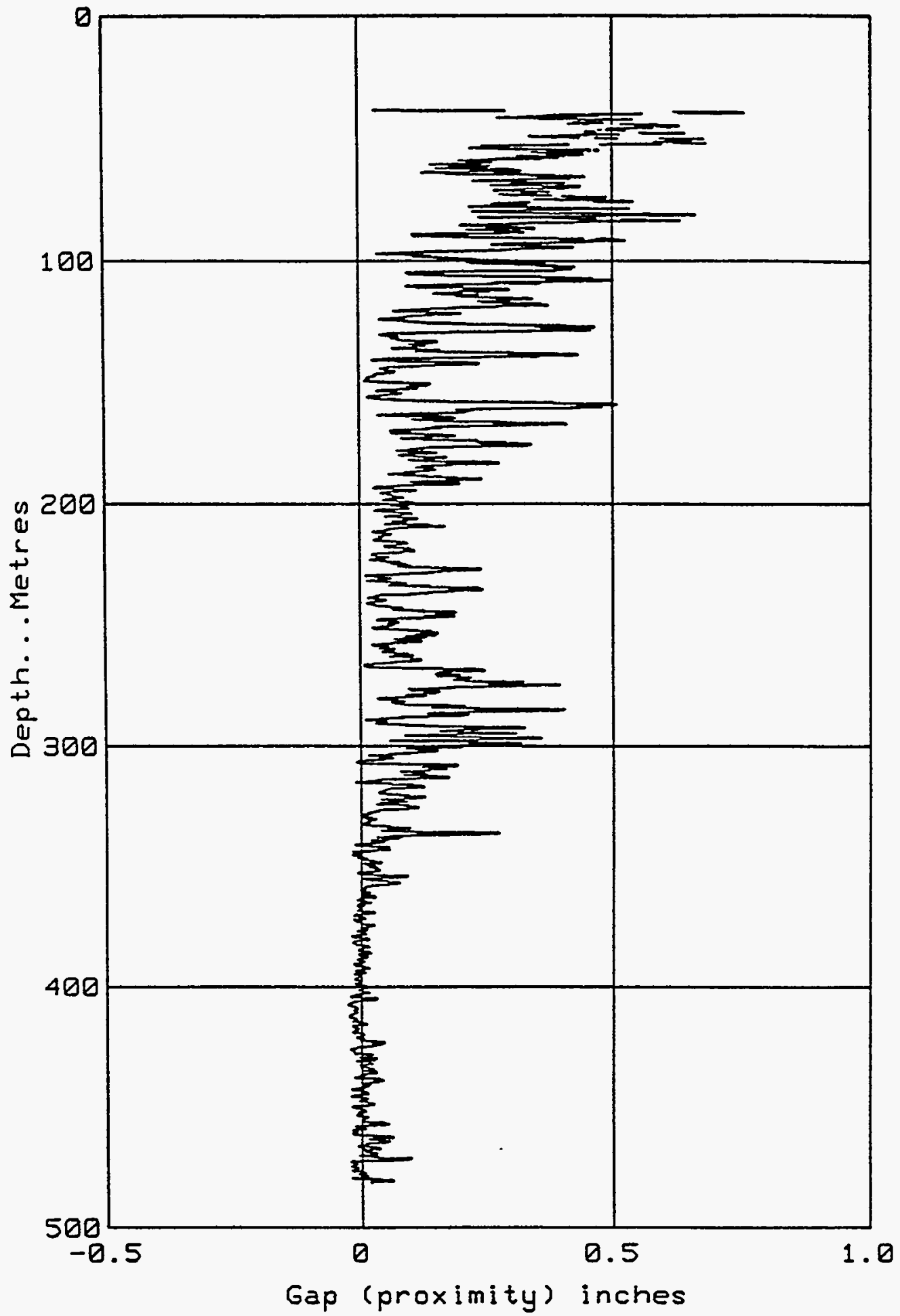

Figure 13. Center sonde-wall gap measured by the DRC sonde in borehole U2fg. Data smoothed with a 1m square smoother. 


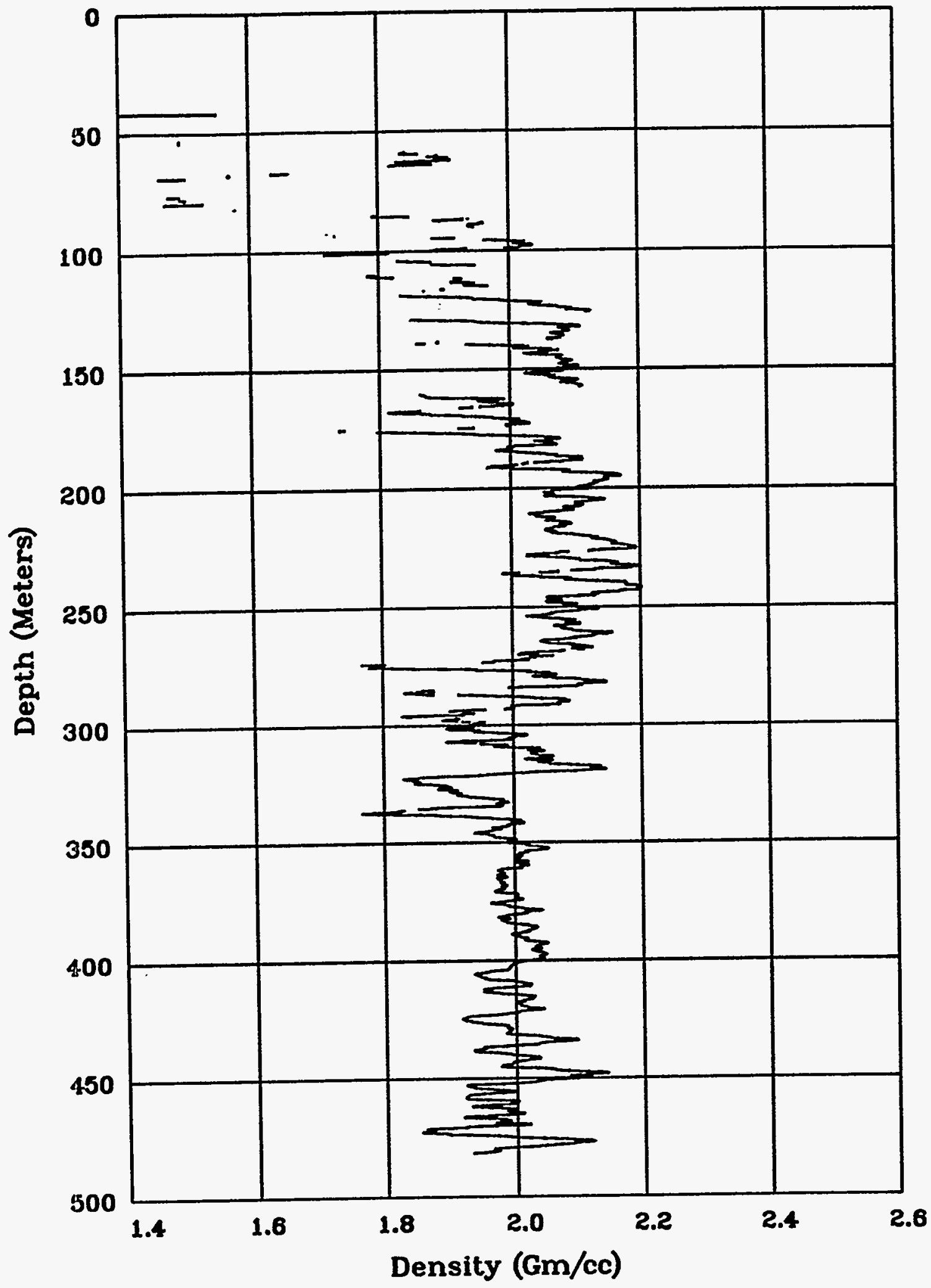

Figure 14. Density from standard processing of the DRC log in borehole U2fg using the center gap measurement. Data smoothed with a 3-m square smoother. 


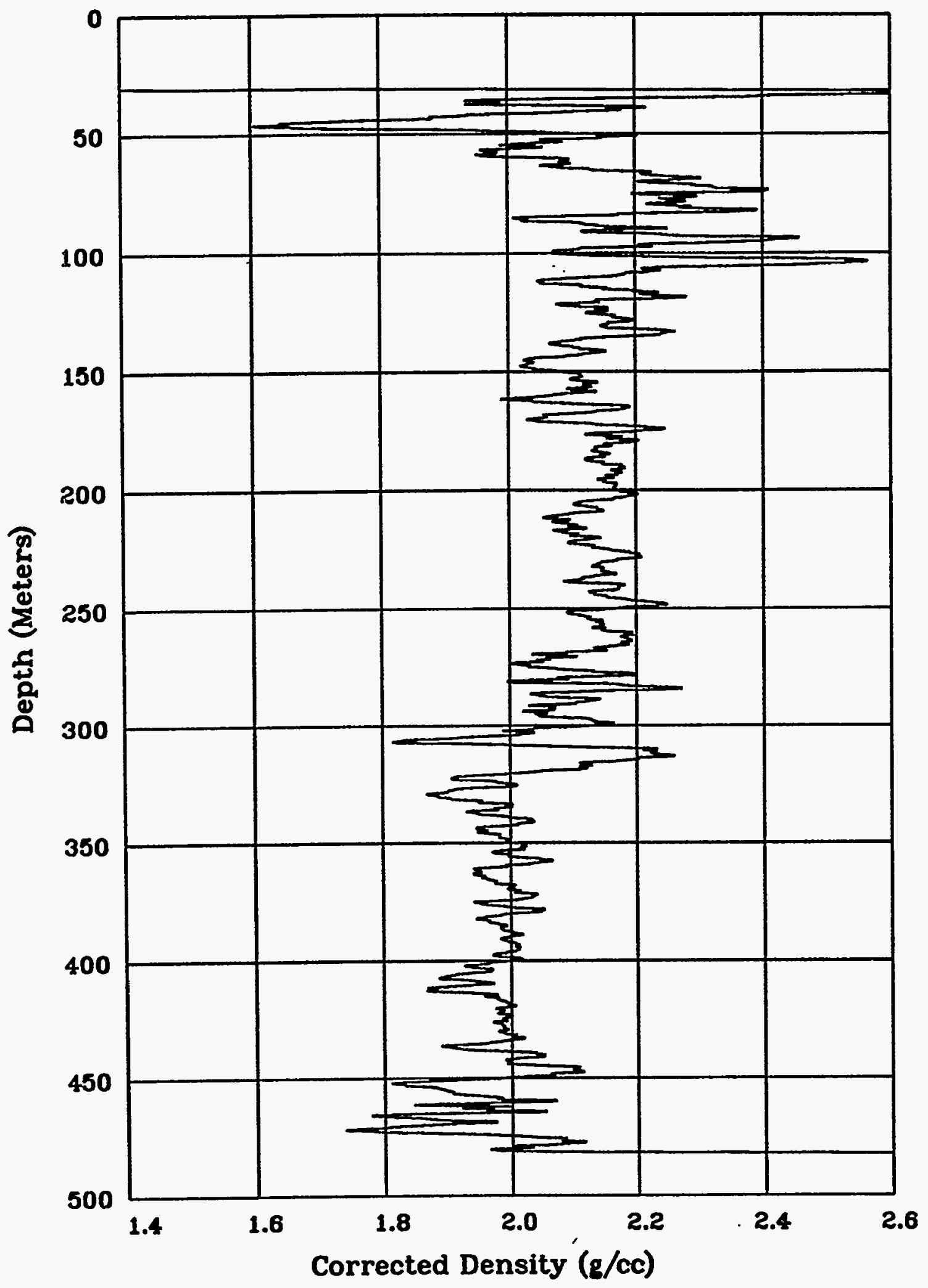

Figure 15. Density from Carlson's (1993) processing of the data from both detectors of the DBS sonde in borehole U2fg. Data smoothed with a 3-m square smoother. 